\title{
O Princípio da Coesão Estrutural na variação da concordância nominal de número em predicativos do sujeito e estruturas passivas do português rural fluminense
}

Jaqueline de Moraes Thurler Dália (UERJ)*

https://orcid.org/0000-0003-3105-1188

\section{Resumo:}

Este trabalho analisou a variação da concordância nominal de número em predicativos do sujeito e estruturas passivas no vernáculo rural de Nova Friburgo-RJ, com base nos pressupostos da Sociolinguística Variacionista. Os dados foram recolhidos em 35 entrevistas realizadas com 16 homens e 19 mulheres; 14, entre 35 e 55 anos; e 21, entre 14 e 19 anos. A quantificação foi realizada com o auxílio do programa Goldvarb. Os condicionamentos estruturais da variação, nesta comunidade de fala, estão ligados ao Princípio de Coesão Estrutural. Constatou-se que a frequência geral de aplicação da regra na comunidade é de $28,3 \%$. Contudo, se SN sujeitos e verbos de uma mesma sentença apresentam os mecanismos de concordância, estes passam a ser replicados em predicativos e particípios numa frequência de $76 \%$. Quando um quantificador é empregado na estrutura predicativa, a coesão se enfraquece, fazendo a concordância cair a menos de 7\%. Outrossim, quando não há concordância de gênero entre sujeito e predicativos/particípios, a de número se apresenta em menos de $9 \%$. Portanto, pode-se concluir que, se as sentenças apresentam concordância no sintagma sujeito e entre ele e o verbo, há maior tendência à utilização das regras de concordância de número em predicativos e estruturas passivas.

Palavras-chave: Variação linguística; Português rural brasileiro; Concordância nominal de número; Predicativos do sujeito; Estruturas passivas.

Resumen:

\section{El Principio de Cohesión Estructural en la variación de la concordancia nominal de número en predicativos y estructuras pasivas del portugués rural en el interior de Río de Janeiro}

* Doutora em Letras (UERJ, 2017). Vínculo institucional: Instituto Federal Fluminense - Campus Avançado Cambuci. Lattes: http://lattes.cnpq.br/7286927182861793. E-mail: jaquelinethurlerdalia@gmail. com / jaqueline.dalia@iff.edu.br 


\begin{abstract}
Este estudio analizó la variación de la concordancia nominal de número en complementos predicativos/participios de los verbos de la pasiva en portugués rural de Nova Friburgo-RJ, basándose en los supuestos de la Sociolingüística Variacionista. Los datos fueron recolectados en 35 entrevistas con 16 hombres y 19 mujeres; 14, entre 35 y 55 años; y 21, entre 14 y 19 años. La cuantificación se realizó con la ayuda del programa Goldvarb. El condicionamiento lingüístico de la variación, en esta comunidad, se conecta al Principio de Cohesión Estructural. Se encontró una frecuencia de aplicación de la regla del 28,3\%. Sin embargo, si los SN sujetos y los verbos de una misma oración presentan los mecanismos de concordancia, ellos se reproducen en complementos predicativos/particípios en una frecuencia del 76\%. Cuando se usa un cuantificador en la estructura predicativa, la cohesión se debilita, lo que hace que la concordancia caiga hasta $7 \%$. Además, cuando no hay concordancia de género entre sujeto y predicativos/participios, la conordancia se presenta en menos del $9 \%$. Se concluye que, si las oraciones presentan concordancia en el sujeto y en el verbo existe una mayor tendencia a utilizar las reglas de concordancia en predicativos y en pasivas.
\end{abstract}

Palabras clave: Variación lingüística; Portugués rural brasileño; Concordancia nominal de número; Complemento predicativo; Estructuras pasivas.

\title{
1. Introdução
}

Os estudos sobre a variação no sistema flexional, seja verbal ou nominal, da Língua Portuguesa têm sido muito produtivos no Brasil. Os processos de concordância vêm sendo, portanto, exaustivamente enfocados pela Sociolinguística Variacionista, que busca, por meio de dados empíricos, demonstrar as características do português brasileiro. Parte-se aqui do pressuposto que o contato linguístico ocorrido no processo de colonização do país e a consequente transmissão linguística irregular de tipo leve afetaram muito significativamente os mecanismos morfológicos de concordância verbal e nominal da língua portuguesa em território nacional (LUCCHESI; BAXTER, 2009).

Essas consequências podem ser observadas mais nitidamente em comunidades mais isoladas, nas quais as condições históricas, geográficas e sociais contribuíram para que as relações sociais se mantivessem densas e multiplex (BORTONI-RICARDO,
2021 e 2011) por muito tempo; e nas quais o aparato estatal, como, principalmente, a estrutura educacional e os meios de comunicação demoraram a chegar e/ou se instalaram de forma insuficiente (LUCCHESI, 2015). Tal processo contribuiu para o baixo ou o tardio acesso à escolarização e ao cotidiano letrado, por exemplo, nas áreas rurais mais afastadas dos grandes centros, nos quais a massificação da escola e o estabelecimento de redes esparsas e uniplex se deu primeiramente (BORTONI-RICARDO, 2021 e 2011).

Em se tratando dos mecanismos e da variação de concordância nominal, as marcas de número vêm apresentando mais variação do que as de gênero. Segundo Lucchesi, esse fenômeno se deve ao caráter redundante da pluralização na Língua Portuguesa, pois

A flexão de número é mais gramatical do que a de gênero, no sentido de que aquela é mais geral do que esta. Diferentemente do que 
ocorre em relação ao gênero, praticamente todos os constituintes do SN se dobram à flexão de gênero. Para além dos determinantes e modificadores, quase todos os nomes e adjetivos se flexionam quanto ao número, ao passo que, para além dos determinantes (artigos, demonstrativos, possessivos, etc.), só os adjetivos de tema _o e um conjunto reduzido de nomes se flexionam quanto ao gênero. (LUCCHESI, 2009, p.375).

Por conta disso, inúmeros são os trabalhos variacionistas que se dedicam a investigar tais processos em distintas comunidades de fala. As investigações giram em torno da (i) variação na concordância de número em sintagmas nominais com base em duas abordagens: atomística (SCHERRE, 1988) ou mórfica, como nos exemplos (1) e (2), e não-atomística ou sintagmática (ANDRADE, 2003; (ANDRADE, 2003; DÁLIA; LUCCHESI, 2021; LUCCHESI; DÁLIA 2021), como em (3) e (4); e (ii) em predicativos e estruturas passivas ou particípios (SCHERRE, 1991; DIAS, 2000; DIAS, 1996; ANTONINO, 2007, 2012 e 2015; LUCCHESI, 2009), como nos exemplos (5) e (6).

(1) ... a água lá é nascente da (-) nossas (+) terra (-)...1. - Marcação ou não marcação de plural em cada item do SN.

(2) [É rural] também por causa dos ( + ) produtores $(+)$ rurais $(+)$. Marcação ou não marcação de plural em cada item do SN.

(3) Eu moro com os meus pais. - Concordância plena no SN.

(4) Que já tem vários emprego, entendeu? - Ausência de concordância no SN.

(5) É, aqui, eles são mais isolados. - Concordância entre predicativo e sujeito.

(6) nós fomo convidado pra ir num casamento - Ausência de concordância entre a estrutura passiva e o sujeito.

1 Todos os exemplos pertencem ao corpus desta análise.
O objetivo deste artigo é, pois, analisar a variação da concordância nominal de número em predicativos do sujeito e estruturas passivas no vernáculo de comunidades rurais de Nova Friburgo, na Região Serrana do Rio de Janeiro, com base nos pressupostos teórico-metodológicos da Sociolinguística Variacionista (WEINREICH; LABOV; HERZOG, 2006[1968]; LABOV, 2008[1972]. O corpus investigado foi construído com base em 35 entrevistas gravadas e transcritas, das quais 16 informantes eram homens e 19 mulheres, de duas gerações distintas - 14 trabalhadores e trabalhadoras rurais, entre 35 e 55 anos; e 21 jovens, entre 14 e 19 anos, filhos e filhas desses agricultores e agricultoras. Todos os informantes nascidos no território investigado. Os dados recolhidos foram quantificados com o auxílio do programa estatístico multivariado Goldvarb.

Embora variáveis sociais e estruturais linguísticas tenham sido testadas na pesquisa, este trabalho circunscreve sua reflexão aos resultados dos grupos de fatores linguísticos, destacando a coesão observada entre os elementos de uma mesma porção do enunciado (LUCCHESI, 2009; LUCCHESI; RIBEIRO, 2009). Para tanto, primeiramente, são apresentados os resultados gerais da variação na concordância nominal de número da comunidade em questão e em outras, a fim de traçar algumas comparações, e os critérios de análise dos predicativos do sujeito e das estruturas passivas. Em seguida, os dados dos fatores linguísticos da concordância são debatidos à luz do Princípio da Coesão Estrutural (LUCCHESI, 2009; LUCCHESI; RIBEIRO, 2009). Por fim, são colocadas as conclusões. Caberá, portanto, a uma outra oportunidade a discussão sobre as questões sociais. 


\section{A concordância nominal de número nos estudos variacionistas do português brasileiro}

Na comunidade examinada, tanto os sintagmas nominais (SN) como os predicativos do sujeito e as estruturas passivas foram submetidos à apreciação e, assim como se observou em outros trabalhos, os últimos estão ainda mais sujeitos à não concordância do que os primeiros. Scherre (1988), por exemplo, utilizando a abordagem atomística, identificou em comunidades urbanas da cidade do Rio de Janeiro a marcação de plural nos itens do SN em um pouco mais de 70\% dos casos. Em contrapartida, quando analisou apenas predicativos e particípios passivos, detectou que a pluralização aconteceu em, aproximadamente, 50\% das ocorrências (SCHERRE, 1991). Na comunidade linguística de Helvécia, no interior da Bahia, extremo oposto ao Rio de Janeiro na polarização sociolinguística do Brasil (LUCCHESI, 2015), notou-se também a queda dos padrões de concordância dos predicativos e passivas quando comparados aos dos SN. Naqueles, as regras foram aplicadas em 1\% dos eventos, de acordo com a pesquisa de Lucchesi (2009), que ainda englobou outras duas comunidades baianas. Nestes, Andrade (2003), baseando-se em uma perspectiva sintagmática, constatou a utilização plena da concordância em $9 \%$ dos casos.

Nas comunidades rurais do $3^{\mathrm{o}}$ Distrito de Nova Friburgo-RJ, a discrepância entre os processos de concordância nominal de número nos SN e nos predicativos do sujeito e estruturas passivas não foi diferente. Como se observa na Tabela 1 , quando analisados sob uma perspectiva mórfica ou atomística, o percentual de marcação de plural em cada item do SN fica em 71,4\%:

Tabela 1 - Frequência da marcação de plural em cada item do SN no português rural da Serra Fluminense

\begin{tabular}{l|c|c|}
\hline \multicolumn{1}{c|}{ Realização de plural } & № de ocorrências/Total & Frequência \\
\hline Com marcação & $2.289 / 3.206$ & $\mathbf{7 1 , 4 \%}$ \\
Sem marcação & $917 / 3.206$ & $\mathbf{2 8 , 6 \%}$ \\
\hline
\end{tabular}

Fonte: LUCCHESI; DÁLIA, 2021.

Quando os SN foram considerados com base na abordagem sintagmática, obtevese uma visão mais realista da aplicação da regra de concordância como um todo, que chegou a uma frequência de 48,1\%, como pode ser percebido na Tabela 2 :

Tabela 2 - Frequência da concordância nominal de número no SN no português rural da Serra Fluminense

\begin{tabular}{l|c|c}
\multicolumn{1}{c|}{$\begin{array}{c}\text { Aplicação da regra de concordância } \\
\text { Abordagem sintagmática }\end{array}$} & № de ocorrências/Total & Frequência \\
\hline Com concordância & $802 / 1.668$ & $\mathbf{4 8 , 1 \%}$ \\
Sem concordância & $866 / 1.668$ & $\mathbf{5 1 , 9 \%}$ \\
\hline
\end{tabular}

Fonte: DÁLIA; LUCCHESI, 2020.

Enfim, observando a pluralização apenas dos predicativos do sujeito e das estruturas passivas, o percentual de concordância fi- cou em 28,3\% das passagens encontradas, conforme o destacado na Tabela 3: 
Tabela 3 - Frequência da concordância nominal de número em predicativos do sujeito e estruturas passivas no português rural fluminense

\begin{tabular}{lc|c}
\hline \multicolumn{1}{c|}{ Aplicação da regra de concordância } & № de ocorrências/Total & Frequência \\
\hline Com concordância & $63 / 223$ & $\mathbf{2 8 , 3 \%}$ \\
Sem concordância & $160 / 223$ & $\mathbf{7 1 , 7 \%}$ \\
\hline
\end{tabular}

Fonte: elaboração própria

A comparação dos resultados desta e de outas pesquisas permite elucidar o cenário linguístico brasileiro no que diz respeito às questões sócio-históricas e também às da estrutura da língua. Nota-se que, em uma realidade urbana de uma grande metrópole na Região Sudeste do país, a frequência da aplicação da regra de concordância nominal de número em predicativos do sujeito e estruturas passivas chega a 50\%, como indica o já citado trabalho de Scherre na cidade do Rio de Janeiro. No interior fluminense, em comunidades rurais, a frequência cai mais de 20 pontos percentuais. Em outra região de grande desenvolvimento econômico, Dias (1996), investigando o fenômeno na capital catarinense e em mais dois municípios do interior - Chapecó e Irati -, encontrou um índice de $43 \%$ de concordância. Já na Bahia, constatou-se um intervalo que vai de $1 \%$, em comunidade mais isoladas marcadas pelo contato linguístico intenso, como se viu nas pesquisas de Lucchesi, 4\% em outras comunidades do interior do estado (ANTONINO, 2015), chegando a perto de $15 \%$ na capital (ANTONINO, 2012). Tais números demonstram o continuum sociolinguístico do português brasileiro que vai desde a quase completa ausência de concordância até a variação estável, na qual duas normas, a popular e a culta, encontram-se em plena competição, colocando a comunidade aqui pesquisada em posição intermediária dessa polarização.

Outrossim, a diferença nos padrões de concordância entre SN e predicativos e es- truturas passivas se dá, de acordo com Lucchesi (2009, p.376), por conta da coesão entre os elementos que os compõem. Nos SN, principalmente nos mais frequentes, formados por determinante seguido de nome, os itens mantêm uma conexão bem mais direta. Como ilustração desse fato, verificou-se que, na comunidade rural fluminense, SN mais simples, constituídos por um determinante ou modificador seguido apenas pelo núcleo, têm uma frequência de aplicação plena da regra de concordância de número sempre maior que a da região que é de $48,1 \%$, variando, portanto, de $50,3 \%$ a $72,2 \%$, a depender do item que se liga ao nome. Todavia, a mera existência de um constituinte à esquerda do núcleo faz a frequência ficar entre 18,8\% e 37,8\% (cf: LUCCHESI; DÁLIA, no prelo) ${ }^{2}$. Já entre o sujeito e seu predicativo ou a estrutura passiva relacionada a ele, a relação é menos coesa porque eles normalmente são separados por um sintagma verbal, especialmente no primeiro caso, ou pela constituição da estrutura perifrástica. Nesse sentido, Lucchesi traça um paralelo entre elementos à esquerda nos SN e a função predicativa, ambos mais refratárias às regras, pois "de acordo com o modelo da Re-

2 Excluíram-se dos resultados discutidos aqui as construções realizadas com numeral devido a seu funcionamento distinto e a sua influência no SN, o que demandaria mais explicações. Contudo, nota-se também que SN constituídos por numeral e nome são plenamente pluralizados em $47,2 \%$ dos casos, o que diminui para $42,9 \%$, quando há elementos depois do núcleo (LUCCHESI; DÁLIA, no prelo). 
gência e Ligação (CHOMSKY,1981, 1986), os predicativos também estariam em adjunção ao SN sujeito, que se moveria para posição de sujeito do verbo de ligação, em estrutura superficial, para receber o caso nominativo" (2009, p.379).

Ademais, como se pode notar nas tabelas, a incidência de predicativos e passivas também é bem menor do que a de SN, o que acaba levando as análises a se debruçarem sobre poucas ocorrências. Scherre, por exemplo, selecionou, em seu corpus de 64 entrevistas, 7.193 SN (1988) e 759 ocorrências de predicativos do sujeito e particípios passivos. Andrade (2003, p.87) contou com 18 inquéritos, apenas da comunidade de Helvécia, que lhe renderam 2.893 SN, enquanto Lucchesi (2009, p.377), com corpora de 36 informantes, divididos entre as comunidades baianas de Helvécia, Cinzento, e Barra e Bananal, levantou 276 casos de predicativos e particípios passivos relacionados a um sujeito no plural. Já no $3^{\circ}$ - Distrito de Nova Friburgo, contou-se com 35 audiências, que contabilizaram 1.668 SN e apenas 223 ocorrências entre predicativos e estruturas passivas.

Antonino (2012) também notou essa baixa produtividade de sentenças predicativas potencialmente pluralizáveis em sua pesquisa na capital baiana. A autora encontrou apenas 239 ocorrências em 60 inquéritos e atribui esse número ao caráter muito pessoal das entrevistas, o que realmente norteia a recolha de dados sociolinguísticos. Todavia, outro aspecto que pode ter contribuído para a pouca incidência de predicativos nesta pesquisa merece ser destacado: a relutância da comunidade de fala rural fluminense em construir expressões valorativas, prototipicamente, construídas a partir de predicados nominais. Dália (2018), abordando a avaliação e o comportamento lin- guístico dessa mesma comunidade, já havia levantado essa questão. Em certos quesitos da pesquisa, um número expressivo de informantes se absteve de fazer julgamentos, positivos ou negativos, em relação à comunidade e à fala. Discursivamente, percebe-se uma tentativa de evasão dessas expressões, como nos exemplos abaixo:

(7) Ah, são gente que gosta muito de ajudá os otros, alguns né? Que têm aqueles também que já são mais... - Agricultora caracterizando as pessoas da comunidade.

(8) São tudo... assim, são tudo agricultô, são tudo bem... são assim - Jovem caracterizando as pessoas da comunidade.

(9) Muitas vezes são mais... pra frente, mais tchan... - Jovem caracterizando adolescentes urbanos em contraposição aos rurais.

Nos excertos, nota-se que inúmeras seriam as ocorrências de predicativos, caso os falantes não tivessem hesitado e interrompido suas falas para evitar avaliações, principalmente, sobre a própria comunidade. Cardoso (2015), também observara, em seus inquéritos no estado de Aracaju, a mesma atitude registrada por Dália, verificando que o aracajuano "não aceita definir superioridade aplicada a certos elementos da linguagem que implicam em um juízo de valor" (CARDOSO, 2015, p.42). Todavia, no que se refere às construções não-predicativas em torno de nomes, os ajuizamentos não são explicitados ou ficam menos evidentes, o que não compromete seu uso.

Em se tratando da variação nos SN, como se pôde observar, alguns resultados já foram apresentados em outros trabalhos. Cabe agora, neste artigo, tratar do fenômeno em predicativos do sujeito e em particípios constituintes das perífrases verbais encontrados no vernáculo da Serra Fluminense. Optou-se por enfocar, apenas, as variáveis linguísticas e aprofundar, por conseguinte, 
a reflexão sobre a relação estrutural da língua. Assim, foram elencados como aspectos a serem considerados os seguintes grupos de fatores:

i. Tipo de predicação - considerandose se a sentença era constituída de predicados nominais, predicados verbo-nominais com predicativos do sujeito, e estruturas passivas. Primeiramente, contou-se também com a codificação de predicativos do objeto, mas por conta de sua estrutura mais complexa, eles foram eliminados da quantificação.

ii. Ordenação da oração - de forma binária, verificando-se se havia ou não alguma modificação na ordem direta dos termos;

iii. Tipo de sujeito - examinando-se se formado por um sintagma nominal simples, um sintagma nominal composto, um pronome pessoal, um sintagma nominal sem núcleo, um pronome relativo e sujeito nulo ou oculto. Sujeitos lexicais com ideia de plural, em um primeiro momento, foram categorizados, porém, como morfologicamente se apresentavam no singular, foram excluídos da análise.

iv. Material interveniente entre verbo e predicativo - diferindo-se a presença ou a ausência de elementos entre os dois constituintes. As características desse material foram consideradas incialmente, mas a categorização binária se mostrou mais produtiva.

v. Concordância nominal de número no sintagma nominal sujeito - avaliando-se se havia ou não a aplicação da regra como um todo no SN nessa função ou ainda se não cabiam me- canismos de concordância no sujeito;

vi. Concordância verbal - analisandose a marcação ou a não marcação de plural no sintagma verbal. Assim, casos em que o verbo foi omitido de todo o enunciado foram descartados da análise, como em situações em que ele estava presente na pergunta realizada pela entrevistadora, mas foi omitido da resposta, que se tornou muito objetiva, formada, apenas, pelo predicativo.

vii. Mecanismos de indicação de plural no sujeito - se indicado por meio de item lexical ou gramatical, por numeral, e ainda se o sujeito era oculto ou composto.

viii. Referência ao falante - considerando-se se o sujeito incluía ou não o emissor;

ix. Caracterização semântica do sujeito - avaliando-se a dicotomia entre humano e não-humano;

X. Estrutura sintagmática do predicativo - se constituído por adjetivo, substantivo, particípio passado, sintagma nominal ou outro modificador (pronomes possessivos, indefinidos, demonstrativos);

xi. Tipo de atributo representado no predicativo - observando-se se essencial ou acidental;

xii. Presença ou ausência do quantificador tudo/todos/todas na estrutura predicativa;

xiii. Saliência fônica de qualquer item do predicativo - subdividindo-se em plural regular e irregular.

xiv. Desvio na concordância de gênero entre sujeito e predicativo ou particípio. Este quesito foi acrescentado no decorrer da análise. 
Após os agrupamentos e reagrupamentos dos fatores, dois testes de rodada no programa estatístico multivariado Goldvarb $\mathrm{X}$ foram realizados: um com todos os grupos e o outro sem o último, por considerar que ele poderia se sobrepor à utilização do quantificador tudo devido à sua neutralidade de gênero. Embora tenham sido bem diversos, após a quantificação realizada, apenas 3 desses conjuntos foram selecionados como estatisticamente relevantes para a análise do fenômeno variável em cada uma das rodadas. Na primeira, concordância verbal, desvio de gênero e concordância no SN sujeito, nessa sequência, foram destacados com significância de .016. Na segunda, a presença do quantificador substituiu a variável de gênero, como o esperado, com uma significância um pouco melhor, .011. Assim como observou Antonino, o "pequeno número de variáveis selecionadas com valor estatístico é esperado" (2015, p.58). Isso se deve ao baixo nível de variação e ao número reduzido de ocorrências, mas também permite que a análise seja mais qualitativa. Sendo assim, os resultados das duas quantificações serão, daqui por diante, apresentadas à luz do Princípio da Coesão Estrutural.

\section{O Princípio da Coesão}

\section{Estrutural na concordância}

nominal de número em

predicativos do sujeito e

estruturas passivas no português rural fluminense.

O Princípio da Coesão Estrutural, postulado por Lucchesi em sua tese (2000), posteriormente desenvolvido em outros trabalhos (2009; 2015), e retomado em Ribeiro e Lucchesi (2009) prevê que, em situações de alternância de código na competência lin- guística do falante, e consequentemente no seu desempenho, há uma propensão a coocorrência de preceitos de uma mesma gramática num mesmo segmento da estrutura oracional. Nos casos de competição entre a norma padrão ou culta e a norma popular, por exemplo, observar-se-ia ora o emprego de uma, ora o emprego de outra, mas com uma tendência de uso da mesma norma numa mesma porção do enunciado. Nessas situações, em que há um convívio entre gramáticas muito semelhantes e inter-relacionadas, típicas da heterogeneidade linguística, a alternância de códigos não seria tão rígida nem categórica, como se observa na concorrência entre línguas distintas (RIBEIRO; LUCCHESI, 2009, p.151). Ou seja, se uma oração é introduzida com a aplicação da regra padrão de concordância nominal de número e gênero no SN sujeito, é provável que haja a marcação correspondente de número e pessoa no sintagma verbal e também de número e gênero nos predicativos e nas estruturas passivas. Todavia, é importante destacar o caráter probabilístico da coesão estrutural, principalmente, entre as normas - mais fluidas - de gramáticas muito parecidas. Portanto, é mais provável que o mesmo registro ocorra em estruturas gramaticais mais relacionais e que nas menos coesas ela seja também menos incidente. Assim:

a regra de concordância de gênero tende a ser menos aplicada em um DP [sintagma determinante] em que não se aplica a regra de concordância de número, do que em um DP em que essa regra é aplicada (...). Isso decorre do fato de que a concordância de número é mais afetada no processo de transmissão linguística irregular do que a concordância de gênero. Assim, é possível postular uma relação de implicação. Ou seja, se em um DP o falante chega a aplicar a regra de concordância de número plenamente, a regra de concordância de gênero será aplicada num 
nível categórico; contudo, o inverso não seria verdadeiro, podendo o falante aplicar a regra de concordância de gênero em um DP, sem que isso leve à aplicação da regra de concordância de número(...).

Já no nível das relações entre constituintes no esqueleto estrutural da sentença, o princípio da coesão estrutural também se aplica, porém com um grau de implicação mais diluído. Tal é o caso da correlação entre a aplicação da regra de concordância de número no DP sujeito e a aplicação da regra de concordância de pessoa e número entre o verbo e este DP sujeito, que especifica os traços de pessoa e número do verbo. Dessa forma, o princípio da coesão estrutural prevê que o falante tenderá a fazer mais a concordância verbal quando fizer a concordância nominal. (RIBEIRO; LUCCHESI, 2009, p.152)

Essa convergência entre os elementos morfossintáticos tem sido frequentemente observada nos processos de variação flexional do português brasileiro, tanto em verbos quanto em nomes, tornando-a bastante profícua na compreensão dos fenômenos variáveis de concordância. Scherre (1988; 1991), por exemplo, analisa em seus trabalhos o paralelismo formal ou o Princípio do Processamento Paralelo, buscando compreender a diferença de pluralização entre predicativos/particípios isolados ou em série, estes precedidos de outros marcados ou não. Faz o mesmo com sujeitos e verbos, primeiro verificando sua presença ou ausência e depois a realização ou não das marcas de plural em cada um deles. A hipótese levantada e testada pela autora é a de que "marcas levam a marcas e zeros levam a zeros" (SCHERRE, 1991, p.54). Em sua tese (1988, p.425), ela coloca tal princípio como candidato a uma regra universal, aplicando-se em quaisquer mecanismos de concordância. Todavia, reconhece que ainda não havia como explicar as motivações, em vernáculos rurais, que levavam à marcação de plural apenas no primeiro elemento dos SN, ou seja, não se compreendia ainda o princípio que não permitia a replicação das marcas para os demais constituintes da estrutura nominal.

Por considerar a harmonização dos mecanismos de concordância como uma tendência e não como uma regra, por admitir que há uma competição entre as próprias normas adotadas pelo falante e que, portanto, essa competição está presente para além dos vernáculos rurais, o Princípio da Coesão Estrutural pareceu mais coerente com a pesquisa aqui desenvolvida. Surpreendentemente, todas as variáveis estruturais linguísticas apontadas como estatisticamente relevantes pelo programa multivariado Goldvarb esbarraram na atuação ou na impossibilidade de ação da coesão estrutural. Elas serão daqui por diante descritas.

\section{1 - A relação entre concordância verbal e a concordância nominal de número em predicativos do sujeito e estruturas passivas.}

A análise dessa vaiável buscava aferir se a realização, como no exemplo (10), ou a não realização da concordância verbal na sentença, como no exemplo (11), interferiria no processo de concordância nominal de número dos predicativos e das estruturas passivas.

(10) Ah, elas são muito simpáticas

(11) os ônibus não era nem tão caro pela prefeitura

Levando em conta o resultado de outros trabalhos que também consideraram esta variável - tanto os que se nortearam pelo Princípio do Paralelismo Formal, como os Scherre (1988; 1991) e os de Dias (1996); quanto os que se basearam na proposição de Princípio da Coesão Estrutural, como os 
de Antonino (2007, 2012, 2015) e Lucchesi (2000; 2009) - esperava-se que as construções com concordância verbal de número e pessoa apresentassem mais concordân- cia nominal de número em predicativos do sujeito e estruturas passivas. 0 resultado consta na Tabela 4:

Tabela 4 - Aplicação da regra de concordância de número em predicativos do sujeito e estruturas passivas no português rural fluminense segundo a concordância verbal.

\begin{tabular}{l|c|c|c}
\hline \multicolumn{1}{c|}{ Concordância verbal } & No de ocorrências / Total & Frequência & Peso Relativo \\
\hline Com concordância verbal & $55 / 146$ & $37,7 \%$ & $\mathbf{6 7 0}$ \\
Sem concordância verbal & $8 / 77$ & $10,4 \%$ & .207 \\
TOTAL & $\mathbf{6 3 / 2 2 3}$ & $\mathbf{2 8 , 3 \%}$ & \\
\hline
\end{tabular}

Nível de significância: .011

Fonte: elaboração própria

Nota-se que a hipótese inicial foi comprovada, já que construções com concordância verbal favoreceram a aplicação da regra de número em predicativos e passivas em $37,7 \%$ das ocorrências, quase 10 pontos percentuais acima do total da comunidade, o que também foi comprovado pelo PR de .670. Como também se esperava, sentenças sem concordância verbal desfavoreceram a nominal. Nestes casos, apenas 10,4\% das construções apresentaram as marcas nominais de plural, com probabilidades de realização diminutas como se comprova com o PR de .207.

Em outros trabalhos, essa tendência também foi observada. Antonino em seu estudo sobre comunidades do interior baiano verificou que: "nas sentenças em que há concordância do verbo em terceira pessoa do plural com o sujeito, maior é a concordância de número entre o sujeito e o seu predicativo ou a estrutura passiva" (2015, p.59), ficando sua frequência em $21 \%$ (mais de 5 vezes acima da média), com PR de .88; e que: "em sentenças em que não há a concordância verbal, também não há a concordância nominal entre os elementos em análise" (2015, p.59), com a frequência caindo para 2\% (metade da média) e PR pra .42. Resultado similar também foi observado em seu estudo em Salvador (2012, p.115), com índices de 29,2\% para o primeiro caso e PR de .750, e 3\%, com PR de .250 no segundo, ressaltando que a frequência geral foi em torno de $15 \%$.

Considerando a atuação das características formais do verbo na concordância dos predicativos e particípios, Scherre concluiu que "verbos marcados favoreceram mais marcas ([PR]0,61) do que os verbos não marcados $(0,18)$ " (1991, p. 61), com frequências de $54 \%$ e 13\%, respectivamente. Todavia, em predicativos coordenados em que o verbo foi considerado "zero", a frequência subiu para $64 \%$ e o PR para 0,74. Nestas situações, a autora considerou outro princípio: um mecanismo de recuperação da informação não expressa morficamente pelo verbo, mas explicitada na marca de plural do predicativo ou do particípio. No entanto, admitiu que mais estudos deveriam ser feitos sob esse aspecto, principalmente, no que diz respeito às características do verbo, que por sua vez poderiam ser relacionadas com as do sujeito. 


\section{2 - A relação entre a presença ou ausência do quantificador e a con- cordância nominal de número em predicativos do sujeito e estruturas passivas.}

Nesta variável a pretensão era detectar se a presença ou a ausência de quantificadores do tipo tudo, todo, toda, todos e todas na estrutura predicativa ou passiva interferiria em seu mecanismo de concordância. Embora os fatores tenham sido categorizados de forma binária - com ou sem quantificador esperava-se que, a presença de tudo inibisse a pluralização plena dos sintagmas formados com seu auxílio, mas a utilização dos outros termos favorecesse a concordância.

A hipótese se baseou no comportamento desses quantificadores nos SN, sem deixar de considerar sua natureza flutuante na estrutura linguística e seu uso no português popular do Brasil (LACERDA, 2012; LOPES, 2009; VICENTE, 2006). Lucchesi e Dália (no prelo), em estudo na mesma comunidade, verificaram que (i) $55,6 \%$ dos SN construídos com quantificadores em suas formas masculina e feminina, realçadoras da ideia de plural, apresentaram a aplicação plena da regra de concordância, com PR bem expressivo de .703, sendo a frequência geral de $48,1 \%$, na região; e que (ii) estruturas construídas com constituintes flexionáveis à direita do núcleo tiveram sua já baixa pluralização ainda mais enfraquecida pela presença da forma neutra, com a frequência de aplicação da regra caindo para $18,8 \%$ e PR de.397.

Os resultados gerais para predicativos e passivas foram os seguintes:

Tabela 5 - Aplicação da regra de concordância de número em predicativos do sujeito e estruturas passivas no português rural fluminense segundo a presença do quantificador tudo/todo(s)/toda(s).

\begin{tabular}{l|c|c|c}
\hline Quantificador tudo/todos & No de ocorrências / Total & Frequência & Peso Relativo \\
\hline Com quantificador & $2 / 30$ & $6,7 \%$ & $\mathbf{. 1 1 1}$ \\
Sem quantificador & $61 / 193$ & $31,6 \%$ & $\mathbf{. 5 8 0}$ \\
TOTAL & $\mathbf{6 3 / 2 2 3}$ & $\mathbf{2 8 , 3 \%}$ & \\
\hline
\end{tabular}

Nível de significância: .011

Fonte: elaboração própria

Novamente, a hipótese geral foi confirmada. A utilização do item desfavoreceu bastante a concordância nominal, já que das 30 ocorrências em que quantificadores foram empregados, apenas 2 apresentaram pluralização plena nos predicativos, ficando a frequência em apenas 6,7\% dos casos e o PR bem baixo, .111. A ausência desses termos, apresenta pouquíssima importância, já que o emprego das regras de concordância nessas porções do enunciado se verificariam por outros critérios estruturais. Essa pouca influência da não utilização dos quantificadores pode ser perce- bida no seu PR de .580, muito próximo de uma neutralidade e da sua frequência em $31,6 \%$, pouco maior do que a da comunidade de fala analisada.

Como foram poucos os casos em que os quantificadores foram usados, foi possível estabelecer também uma análise qualitativa dos sintagmas construídos com eles. Em todos os casos, eles assumiram a posição interveniente entre o verbo e o núcleo do predicativo/estrutura passiva, ou seja, à esquerda do núcleo, seja ele exercido por um adjetivo, locução adjetiva, substantivo ou particípio, como nos exemplos (12) e (13): 
(12) os pasto aqui, com meu pai e meu irmão, era tudo roçado.

(13) nós somos todos iguais, independente de tê dinheiro.

Levando-se em conta a premissa de que em SN o determinante à esquerda é o item que mais recebe marcas de plural (SCHERRE, 1988; GUY, 1981; BAXTER, 2009; LUCCHESI; DÁLIA, no prelo), era possível que o quantificador nessa posição também fosse pluralizado. Todavia, quando se observa a natureza morfológica desse termo, nota-se a impossibilidade de uso de tais morfemas. Das 30 ocorrências, 25 foram construídas com tudo, forma neutra, desprovida de indicações de gênero e número e, consequentemente, de possibilidades de aplicação da regra de concordância.

Por conta dessa característica, a forma neutra também impede a harmonização entre as flexões de uma mesma sentença. Isso não aconteceu, por exemplo, no único caso em que o quantificador foi utilizado no feminino e no plural, observando-se, aí, o emprego de todas as regras de concordância em um mesmo enunciado:

(14) Não, acho que [as localidades] são todas parecidas.

Já com as quatro ocorrências da forma marcadamente masculina, não houve como fazer qualquer suposição para além da varação estável, pois em duas houve concordância de número e nas outras duas não. Em síntese a atuação do Princípio da Coesão Estrutural no emprego pleno da norma é bloqueada pela utilização do quantificador neutro, uma vez que ele não permite a marcação, especialmente, de número em todos os elementos constituintes de uma mesma porção do enunciado.

\section{3 - A relação entre a variação na concordância de gênero e a con- cordância nominal de número em predicativos do sujeito e estruturas passivas.}

Não havia previsão de se analisar a concordância de gênero na pesquisa, principalmente, porque os desvios dessa flexão ocorrem em baixíssima frequência e não sustentariam, a princípio, uma verificação quantitativa. Apenas 36 sentenças apresentaram variação nesse aspecto. Todavia, como é um fenômeno bastante raro, não se podia desprezar o fato de que cerca de $16 \%$ dos enunciados examinados não apresentaram concordância de gênero entre o sujeito e seu predicativo ou estrutura passiva, como se nota nos seguintes exemplos:

(15) a (nome ocultado) e eu somos filho do papai e da mamãe junto. (Falante mulher referindo-se a ela e sua irmã).

(16) tem essas pessoas também que são caracterizados pelo modo de vesti.

Diante da observação, optou-se por controlar também essa variável e em praticamente todos os testes de rodadas, o grupo de fatores foi selecionado pelo programa como significativo para os processos de concordância. A hipótese geral previa que, tendencialmente, a não concordância de gênero, por ter sido menos afetada no processo de transmissão linguística irregular e, por isso, demonstrar menos variação, apresentar-se -ia em contextos de não aplicação plena das marcas de plural, mais propícia a alterações. Pelo mesmo motivo, considerou-se também que a harmonização nos mecanismos de flexão de gênero não garantiria a de número (RIBEIRO; LUCCHESI, 2009, p.152). Seguem os números: 
Tabela 6 - Aplicação da regra de concordância de número em predicativos do sujeito e estruturas passivas no português rural fluminense frente à concordância de gênero na estrutura.

\begin{tabular}{l|c|c|c}
\hline Concordância de gênero no SN sujeito & № de ocorrências / Total & Frequência & Peso Relativo \\
\hline Com concordância de gênero & $60 / 187$ & $32,1 \%$ & $\mathbf{. 6 0 1}$ \\
Sem concordância de gênero & $3 / 36$ & $8,3 \%$ & $\mathbf{. 1 0 7}$ \\
TOTAL & $\mathbf{6 3 / 2 2 3}$ & $\mathbf{2 8 , 3 \%}$ & \\
\hline
\end{tabular}

Nível de significância: .016

Fonte: elaboração própria

A tendência prevista foi confirmada. Das 36 ocorrências com incongruência na concordância de gênero, apenas 3 apresentaram todas as marcas nominais de número. Esse contexto constitui 8,3\% dos casos, ou seja, sua frequência foi 3,4 vezes menor que o total da comunidade, com PR de .107, demonstrando pouquíssima possibilidade de registro da segunda sem o da primeira. Verificou-se, portanto, a relação de implicação colocada por Lucchesi e Ribeiro (2009, p.152), em que situações de plena pluralização formam um contexto propício à concordância de gênero, ainda que ela não tenha sido categórica, como se observa no exemplo (16). Já quando houve concordância de gênero, a frequência da de número ficou em $32,1 \%$ e o PR subiu consideravelmente, ficando em .601.

Esses números confirmam também o segundo prognóstico de que a realização das flexões de gênero não provoca necessariamente a concretização das de número. Novamente, percebeu-se a atuação do Princípio da Coesão Estrutural, no qual se identificou a mesma disposição das demais variáveis. Vale ressaltar que das 36 sentenças, 13 (mais de 1/3) foram constituídas com a forma tudo. Daí a grande influência desse elemento no bloqueio da aplicação da regra, principalmente em casos de nomes femininos plurais.

Por fim, Lucchesi chama atenção para o fato de que estudos sobre variação de gêne- ro são praticamente inexistentes nas variedades urbanas, o que "indica a falta de um nível significativo de variação" (LUCCHESI, 2009, p.386). Já em comunidades rurais afro-brasileiras do interior da Bahia, ela foi encontrada, e controlada, em $20 \%$ de ocorrências com sujeito feminino. Essa variável não foi ponderada com tanta rigidez científica aqui. Notese que todos os casos de não concordância de gênero, $16 \%$, foram observados à luz de contextos plurais, não retratando, portanto, o real cenário de variação na comunidade. Em princípio, parece não haver uma grande variação no uso desse mecanismo flexional, mas somente um estudo direcionado a ele poderia dar subsídios para uma contundente conclusão a respeito. Entretanto, não deixa de ser importante registrar o fenômeno e o efeito dele na harmonização flexional em mais uma comunidade rural do Brasil.

\section{4 - A relação entre a concordância nominal de número no $\mathrm{SN}$ sujeito e em predicativos do sujeito e estru- turas passivas.}

Também tendo como hipótese o Princípio da Coesão Estrutural, a expectativa era a de que sentenças com concordância nominal no sujeito, como em (17), apresentassem a mesma marcação morfológica nos predicativos e nas estruturas passivas, assim como a premissa contrária, com sujeito sem concordância, como em (18), também se aplicaria. 
(17) ...até as pessoas adolescentes da cidade são diferentes da da área rural.

(18) ...no Fundamental, as coisa era mais fácil.

Todavia, não se deixou de analisar ainda contextos em que não se podia realizar qualquer tipo de concordância no sujeito, por exemplo, nos casos de sujeito nulo (19), sujeito pronominal (20), ou ainda alguns sujeitos compostos (21).

(19) Bom... em parte é, agora já tão mais idoso. (Referindo-se aos avós).

(20) É, aqui, eles são mais isolados.

(21) Aí, meu pai e minha mãe sempre foi muito fechado.

Todos esses episódios foram categori- zados em um mesmo grupo e o esperado era que eles também estimulassem mais pluralizações devido à transparência semântica. Em tais situações, itens lexicais ou sujeitos pronominais guardam relação mais direta, por isso transparente, com sua ideia de plural (LUCCHESI; BAXTER; SILVA, 2009, p.352), reforçada no predicativo ou no particípio com as marcas morfológicas de número. Já sujeitos nulos tenderiam a ter essas características retomadas e/ou marcadas em outros itens, como verbos ou predicativos, por meio de suas flexões.

Os resultados confirmaram todas as suposições iniciais, como se vê na Tabela 7:

Tabela 7 - Aplicação da regra de concordância de número em predicativos do sujeito e estruturas passivas no português rural fluminense segundo a concordância de número no SN sujeito.

\begin{tabular}{l|c|c|c}
\hline \multicolumn{1}{c|}{ Concordância no SN sujeito } & No de ocorrências / Total & Frequência & Peso Relativo \\
\hline Com concordância de número & $15 / 30$ & $50 \%$ & $\mathbf{. 7 3 5}$ \\
Casos em que não cabia a concordância & $47 / 157$ & $29,9 \%$ & $\mathbf{. 5 6 4}$ \\
Sem concordância de número & $1 / 36$ & $2,8 \%$ & $\mathbf{. 1 2 1}$ \\
TOTAL & $\mathbf{6 3 / 2 2 3}$ & $\mathbf{2 8 , 3 \%}$ & \\
\hline
\end{tabular}

Nível de significância: .011

Fonte: elaboração própria

Construções com concordância nominal plena no SN sujeito apresentaram uma frequência de marcação de plural nos predicativos e estruturas passivas de $50 \%$, o que compreende mais de 20 pontos percentuais acima do total da comunidade, com um PR bem significativo de.735. Como o esperado, o não emprego da regra no SN sujeito desmotivou expressivamente a pluralização nos outros termos, caindo para uma frequência de apenas 2,8\% de pluralizações nesses casos, com baixíssima probabilidade de ocorrência, de acordo com seu PR de .121. Já nas sentenças em que não cabiam os mecanismos de concordância no sujeito, houve um leve, mas não relevante, favorecimento da marcação de número em predicativos e estruturas passivas, indicado pela frequência de $29,9 \%$ e PR de .564 .

Tal tendência também foi observada em outras pesquisas. Antonino (2015) considerou apenas a dicotomia entre sujeito com e sem concordância e detectou que a pluralização plena do sujeito favoreceu a frequência de marcação em predicativos e estruturas passivas em $19 \%$ dos casos, com PR .88 (lembrando que a média de emprego da norma no interior baiano foi de 4\%); e a não pluralização desfavoreceu, fazendo o indicador cair para 2\%, com PR de .39. Já na capital, as frequências foram de $34,8 \%$, mais que o dobro da média, e PR de .780, 
para sentenças em que houve aplicação da regra no SN sujeito; e 3,6\%, com PR de .220, nas que não apresentaram essa condição (ANTONINO, 2012, p.114). Scherre (1991, p.58) detectou que sujeitos explícitos com todas as marcas de plural favorecerem a concordância de predicativos/particípios em $57 \%$ dos episódios; seguidos por sujeito zero, 53\%; em oposição a sujeitos sem todas as flexões com $21 \%$ de frequência.

Essa variável explanatória juntamente com os fatores de concordância verbal suportam o Princípio da Coesão Estrutural, nesta e em várias pesquisas. Quando os dados dos dois grupos são cruzados a sustentação se torna ainda mais clara:

Tabela 8 - Aplicação da regra de concordância de número em predicativos do sujeito e estruturas passivas no português rural fluminense segundo a atuação conjunta da concordância de número no SN sujeito e da concordância verbal.

\begin{tabular}{lc|c|c|c|c|c}
\hline & \multicolumn{2}{c|}{$\begin{array}{c}\text { SN sujeito sem } \\
\text { concordância }\end{array}$} & \multicolumn{2}{c|}{$\begin{array}{c}\text { Sujeito sem possibilidade } \\
\text { de concordância }\end{array}$} & \multicolumn{2}{c}{$\begin{array}{c}\text { SN sujeito com } \\
\text { concordância }\end{array}$} \\
\cline { 2 - 7 } & Ocorrências & Frequência & Ocorrências & Frequência & Ocorrências & Frequência \\
\hline $\begin{array}{l}\text { Sem conc. } \\
\text { verbal }\end{array}$ & 0 & $0 \%$ & 6 & $15 \%$ & 2 & $15 \%$ \\
$\begin{array}{l}\text { Com conc. } \\
\text { verbal }\end{array}$ & 1 & $8 \%$ & 41 & $35 \%$ & 13 & $76 \%$ \\
\hline
\end{tabular}

Fonte: elaboração própria

Nota-se que, em contextos em que não houve concordância nominal de número plena no SN sujeito nem concordância verbal, também não houve nenhuma pluralização dos predicativos. Em contrapartida, a frequência de marcação de plural em predicativos e estruturas passivas foi a $76 \%$, quando a regra também foi aplicada nos sujeitos e nos verbos. Na pesquisa de Antonino, as variáveis concordância nominal no SN sujeito e concordância verbal também confirmaram tal princípio, uma vez que "ficou nítido que os contextos que exibiam as marcas de plural, como o sujeito e o verbo marcados, favoreceram também a marcação de plural nos predicativos e nas estruturas passivas" (2015, p.59). Os números apresentados de forma cruzada parecem, pois, comprovar a coesão estrutural como uma forte tendência em uma mesma sentença, mas não necessariamente como uma regra, visto que também ocorreram situações em que sujeitos e verbos foram marcados, mas não levaram as mesmas marcas a predicativos e particípios.

\section{Considerações finais}

No decorrer deste trabalho, procurou-se delinear o quadro atual da variação na concordância nominal de número em predicativos do sujeito e nas estruturas passivas do português popular rural do município de Nova Friburgo, na Região Serrana do Rio de Janeiro. Entende-se que as variações encontradas na Língua Portuguesa em território brasileiro são fruto de um intenso contato linguístico, já estabelecido na Colônia, principalmente entre portugueses, indígenas e africanos aqui escravizados das mais diversas etnias, que resultou na transmissão linguística irregular de tipo leve entre os aqui chegados não falantes do idioma do dominador.

0 reflexo mais nítido desse processo foi a erosão do sistema flexional de nomes e verbos característica do português brasileiro, 
indicadora da polarização sociolinguística, na qual em um extremo se encontra a norma culta e no outro a norma popular. Entretanto, observa-se também um contínuo nivelamento desses padrões, motivado pela ampliação da rede educacional, pelo melhoramento do acesso à comunicação e pela melhoria das condições de mobilidade. Isso se nota, quando se comparam os padrões de uso, por exemplo, de distintas gerações e regiões do país.

A comparação estabelecida na pesquisa permitiu observar que a comunidade investigada se encontra em um nível intermediário no continuum da variação de concordância nominal do português brasileiro. Em regiões metropolitanas, a aplicação das regras de pluralização em predicativos e estruturas passivas está estável, girando em torno de $50 \%$, e, em comunidades mais isoladas dos grandes centros, ela pode ainda ser residual, perto de $1 \%$. Já no interior fluminense, a frequência de usos das regras desses termos é de 28,3\%.

Nesta comunidade de fala, os condicionamentos estruturais que delineiam a variação estão ligados ao Princípio de Coesão Estrutural. Constatou-se que, embora o nível geral de aplicação da regra seja baixo, quando, numa mesma sentença, $\mathrm{SN}$ sujeitos e verbos apresentam os mecanismos flexionais, eles passam a ser replicados em predicativos e particípios numa frequência de 76\%. Todavia, quando o quantificador 'tudo' é empregado na estrutura predicativa, por conta de sua neutralidade de gênero e número, tal princípio é enfraquecido, fazendo a concordância, nessas porções do enunciado, cair a menos de 7\%. Outro fator que também comprovou a atuação da coesão estrutural é a convergência entre flexões de gênero e número. Em contextos enunciativos em que não houve concordância de gênero entre sujeito e predicativos/particípios, a de número foi realizada em menos de 9\% das sentenças.

Portanto, pode-se concluir que há uma maior tendência à utilização das regras de concordância de número em predicativos e estruturas passivas, quando as sentenças também apresentam concordância de gênero e número no sujeito e número e pessoa no verbo. A premissa inversa também é verdadeira. Quando os enunciados iniciam sem a aplicação dos padrões de concordância no sujeito, a ausência de marcas nos verbos e nos predicativos/particípios tendem a se manter. Em casos em que não houve concordância nem no SN sujeito nem no verbo, a marcação zero no predicativo foi categórica. Contudo, quando há uma necessidade de transparência semântica por conta da utilização de sujeitos pronominais ou pela não explicitação do sujeito na sentença, as marcas em predicativos tendem a aumentar, assegurando assim relação transparente com o item lexical do sujeito ou marcação/ retomada da ideia de plural ao final da predicação.

Cabem, a partir de agora, outras reflexões, principalmente, voltadas aos condicionamentos sociais dessa variação. Supõe-se que o papel das mulheres, especialmente as mais jovens, da escola e das comunidades de prática podem estar interferindo nos padrões de concordância da região. Todavia, esses aspectos carecem de mais espaço para análises mais aprofundadas, o que será feito em outra oportunidade.

\section{Referências}

ANDRADE, Patrícia Ribeiro de. Um fragmento da constituição sócio-histórica do português do Brasil: variação na concordância nominal de número em um dialeto afro-brasileiro. 2003. 147f. Dissertação (Mestrado em Letras e Linguística) - Instituto de Letras, Universidade Federal da 
O Princípio da Coesão Estrutural na variação da concordância nominal de número em predicativos do sujeito e estruturas passivas do português rural fluminense

Bahia, Salvador, 2003.

ANTONINO, Vivian. O português popular do interior do estado da Bahia: um estudo da concordância nominal de número e de gênero. Cuadernos de la ALFAL, Niterói, n. 7, p.53-67, Março 2015.

ANTONINO, Vivian. Português popular de Salvador: uma análise da concordancia nominal em predicativos e em estruturas passivas. 2012. 190f. Tese (Doutorado em Letras e Linguística) - Instituto de Letras, Universidade Federal da Bahia, Salvador, 2012.

ANTONINO, Vivian. A concordancia nominal em predicativos e em estruturas passivas no português popular do interior do estado da Bahia. 2007. 119f. Dissertação (Mestrado em Letras e Linguística) - Instituto de Letras, Universidade Federal da Bahia, Salvador, 2007.

BAXTER, Alan. A concordância de número. In: LUCCHESI; Dante; BAXTER, Alan; RIBEIRO, Ilza (orgs.). O Português Afro-Brasileiro. Salvador: Edufba, 2009. p. 269-294.

BORTONI-RICARDO, Stella Maris. Do campo para a cidade: estudo sociolinguístico de migração e redes sociais. São Paulo: Parábola Editorial, 2011.

BORTONI-RICARDO, Stella Maris. Português brasileiro: a língua que falamos. São Paulo: Contexto, 2021.

CARDOSO, Denise Porto. Atitudes linguísticas e avaliações subjetivas de alguns dialetos brasileiros. São Paulo: Blucher, 2015.

DÁLIA, Jaqueline de Moraes Thurler; LUCCHESI, Dante. A variação na concordância de número no sintagma nominal no português rural da serra fluminense: deriva ou contato? Revista Gragoatá, Niterói, v.26, n. 54, p.217-251, Jan.-Abr. 2021.

DÁLIA, Jaqueline de Moraes Thurler. Atitudes, crenças e (auto)avaliação linguística de comunidades do $3^{\circ}$ Distrito de Nova Friburgo. Caderno Seminal Digital Especial, Rio de Janeiro, v. 30, noㅡ 30, p.345-399, Jan-Dez. 2018.

DIAS, Juçá Fialho Vazzata. A concordância de número nos predicativos e particípios passados na fala da Região Sul: um estudo variacionistas. 1996. 123f. Dissertação (Mestrado em Letras e Linguística) - Universidade Federal de Santa Catarina, Florianópolis, 1996.

DIAS, Juçá Fialho Vazzata. A concordância de número nos predicativos/particípios passados na fala Sul do Brasil: motivações extralinguísticas. Letras de Hoje, Porto Alegre, v.35, no1, p.209228, Março de 2000.

GUY, Gregory. Linguistic variation in Brazilian Portuguese: aspects of the phonology, syntax, and language history. Dissertation (PHD in Linguistics) - University of Pennsylvania, Philadelphia, 1981.

LABOV, William. Padrões Sociolinguísticos. São Paulo: Parábola, 2008[1972].

LACERDA, Renato. Quantificadores flutuantes no português brasileiro. 2012. 138f. Dissertação (Mestrado em Letras/Linguística) - Faculdade de Filosofia, Letras e Ciências Humanas, Universidade de São Paulo, São Paulo, 2012.

LOPES, Norma da Silva. A interferência do tudo no valor de todos/todas na concordância do português. Anais [do] XX Jornada Nacional de Estudos Linguísticos, João Pessoa, 2004.

LUCCHESI, Dante; DÁLIA, Jaqueline de Moraes Thurler Dália. Novos condicionamento estruturais da variação na cocncordância nominaal de número. Revista Fórum Linguístico, Florianópolis, no prelo.

LUCCHESI, Dante. Língua e Sociedade Partidas: a polarização sociolinguística do Brasil. São Paulo: Contexto, 2015.

LUCCHESI; Dante; BAXTER, Alan; RIBEIRO, Ilza (orgs.). O Português Afro-Brasileiro. Salvador: Edufba, 2009.

LUCCHESI, Dante; BAXTER, Alan. A transmissão Linguística Irregular. In: LUCCHESI; Dante; BAXTER, Alan; RIBEIRO, Ilza (orgs.). O Português Afro-Brasileiro. Salvador: Edufba, 2009. p. 101-124.

LUCCHESI; Dante; RIBEIRO, Ilza. Teorias da estrutura e da mudança linguísticas e o contato entre línguas. In: LUCCHESI; Dante; BAXTER, Alan; RIBEIRO, Ilza (orgs.). O Português Afro -Brasileiro. Salvador: Edufba, 2009. p. 125-154.

LUCCHESI, Dante. A concordância de gênero. In: LUCCHESI; Dante; BAXTER, Alan; RIBEIRO, Ilza 
(orgs.). O Português Afro-Brasileiro. Salvador: Edufba, 2009. p. 295-318.

LUCCHESI, Dante; BAXTER, Alan; SILVA, Jorge Augusto Alves. A concordância verbal. In: LUCCHESI; Dante; BAXTER, Alan; RIBEIRO, Ilza (orgs.). O Português Afro-Brasileiro. Salvador: Edufba, 2009. p. 331-372.

LUCCHESI, Dante. A variação na concordância de gênero em uma comunidade de fala afro-brasileira: novos elementos sobre a formação do português popular do Brasil. 2000. 364f. Tese (Doutorado em Linguística) - Faculdade de Letras, Universidade Federal do Rio de Janeiro, Rio de Janeiro, 2000.

SCHERRE, Marta. A concordância de número nos predicativos e nos particípios passivos, Porto Ale- gre, v. 18, p.52-70, 1991.

SCHERRE, Marta. Reanálise da Concordância Nominal em Português. 1988. 554f. Tese (Doutorado em Linguística) - Faculdade de Letras, Universidade Federal do Rio de Janeiro, Rio de Janeiro, 1988.

VICENTE, Helena da Silva Guerra. O quantificador flutuante todos no português brasileiro $e$ no inglês: uma abordagem gerativa. 2006. 182f. Tese (Doutorado em Linguística) - Faculdade de Letras, Universidade de Brasília, Brasília, 2006.

WEINREICH, Uriel; LABOV, William; HERZOG, Marvin. Fundamentos empíricos para uma teoria da mudança linguística. São Paulo: Parábola, 2006[1968].

Recebido em: 10/04/2021

Aprovado em: 10/08/2021 